\title{
Case Reports and Confidentiality Opinion is Sought, Medical and Legal
}

\author{
GREG WILKINSON, TOM FAHY, GERALD RUSSELL, DAVID HEALY, ISAAC MARKS, \\ DIGBY TANTAM and BRIDGIT DIMOND
}

The British Journal of Psychiatry's “'Instructions to Authors" regarding case reports and confidentiality (as from the January 1994 issue) are as follows:

"If an individual patient is described, his or her consent should be obtained. The patient should read the report before submission. Where the patient is not able to give informed consent, it should be obtained from an authorised person. Personal details and dates should be kept to a minimum. If necessary, personal details should be changed to disguise the patient if this is consistent with accurate reporting of the clinical data, and a note should be added to the paper to this effect."

These instructions have aroused some controversy and, as may be seen from the invited contributions collected below, the interests of patients and doctors may be divergent, and Editors need to be wary of their position in law.

\section{Clinical opinion}

\section{Gerald Russell}

The Editors of the $B J P$ are right to set ground rules for the publication of psychiatric case reports. A detailed case history can act as a fingerprint and lead to recognition of the patient, thereby causing hurt or even harm. On the other hand, the Editors should take care not to discourage the publication of case reports, as psychiatric patients themselves are the origin of new knowledge in psychiatry.

I shall provide an illustrative case history. In 1972, together with three colleagues, I published a case report in a psychiatric journal which was sensationally transcribed by a popular newspaper. The report was on a not-so-young man who had developed an unusual endocrine disorder causing sexual impotence associated with depression. After a control trial of placebo we treated him with testosterone. He responded with a rapid return of sexual interest, which we were able to measure. The psychological aspects of the recovery merited publication. We did not seek consent because in 1972 we did not foresee the possibility of this patient stumbling on his own story while reading his newspaper. This is indeed what happened: his distress was such as to leave an indelible impression on my memory.

Patients' consent should therefore be obtained if there is any chance of recognition. However, the $B J P$ 's requirements go too far in making consent mandatory for all case reports. The psychiatric literature has gradually become impoverished by editorial reluctance to publish case reports, and the Instructions to Authors, unless modified, will further impede their publication.

Disguising a psychiatric history can be a poor solution, as it opens the door to misleading inventiveness. I believe that the above abbreviated case report will not permit identification, because I have omitted personal details and clinical information. The latter omission weakens the case report, of course, but this does not matter as this commentary serves an ethical rather than a scientific purpose. Hence I have once again not sought the patient's consent to publish.

\section{David Healy}

Some of the most significant research in psychiatry has been conducted in the form of case reports, from Freud's case histories through to Michael Shepherd's studies of morbid jealousy. In general, the usefulness of these reports is related directly to the extent to which they provide pertinent social and phenomenological detail. In some cases this has meant that historians have subsequently been able to determine the identity of those whose cases are described.

Until quite recently, even in the case of drug studies, many journals have felt that the proper reporting of such studies has required detailing a patient's case history rather specifically. In these days of double-blind randomised placebo-controlled trials, the need for idiographic approaches seems less apparent, but it is unlikely that it will ever go away completely.

At present I am part of a research group bringing to completion a project concerning cognitive therapy for delusions. The wealth of data in this project is such that it cannot be adequately reported in the form of mean scores on rating scales. In order to do 
justice to the data, some of it will need to be written up as case reports. While it is my practice to copy all correspondence on a particular patient to the patient, given that delusional disorders frequently involve a morbid sensitivity, I would envisage a number of individuals objecting to their cases being reported, even in a disguised form.

Equally, I would imagine that in many cases involving a sexual or forensic element, that the subjects of these reports will not give their consent to a well disguised report. What would happen if one wished to describe a new variation of Munchausen's syndrome, for instance?

While there is clearly a need for discretion in the reporting of personal details, the guidelines on confidentiality put forward by the $B J P$ are ambiguously phrased. If injudiciously interpreted, there would seem to be a risk that these guidelines will inhibit the detailing of what might be important research.

\section{Isaac Marks}

I fear it will rather discourage case reports if written consent becomes necessary in all cases, and lead to fewer reports being made of clinically important observations or innovations. Case reports are commonly written long after the patient was last seen, so the patient may not be traceable, or traceable only after considerable effort. The need for such additional effort will discourage clinicians from making potentially valuable reports to their peers, and so retard improvements in clinical care. This would be unfortunate.

It is difficult to see why previous practice should be changed. Consent should surely not be needed if all personal details are omitted. There is no reason to expect the patient's identity to be recognised from such a report by anyone except perhaps the patient, who might link the report just to the author's name. Given that patients can now access their case notes, that should be no cause for concern. I have published numerous case reports in the $B J P$ and other journals, and never had a complaint about it.

\section{Digby Tantam}

I welcome the $B J P$ giving clearer advice to the authors of case reports, and the principle that patients should give their consent to the publication of any personal information about them. Other psychotherapists also take this position, and indeed the Ethical Guidelines of the United Kingdom Council for Psychotherapy state that psychotherapists must safeguard the welfare and anonymity of clients when any form of publication of clinical material is being considered and to obtain their consent whenever possible.

In most situations, the guidelines will work well. The patient, who it will be assumed will be of sound mind, and able to give informed consent, will read the report without prejudice and give useful feedback, for example the correction of factual details. The fact that the patient is reading the report will make the reporter more sensitive to the patient's feelings and will probably result in the removal of unnecessary personal details. In the majority of cases, the author will know which details are important, and which can be omitted or, in order to conceal the patient's identity even more effectively, changed.

I am therefore pleased with the statement, but I wonder whether it entirely covers those cases where the situation is not so straightforward. Who is to determine when a patient can give informed consent and, when patients cannot give informed consent, what is the nature of the authorisation? Does the need for consent apply after a person has died? Case reports of suicide or unexpected death are important in psychiatry, but can have a distressing effect on the next of kin. Is there a duty to obtain their consent? A few years ago a colleague and I (Ekkehart Stauffenberg) published a letter in the BJP concerning a patient of ours who died of a serotonin reaction. This was completely new to us at the time, and we felt that others should be made aware of it. I think that we would have wanted to publish the paper whatever the relatives thought, because of its potential impact on the care of other patients. Do we know which clinical data, or which personal details, can be disguised or omitted without affecting future science? The first scientific validation of death by broken heart was based on a comparison of the dates of death on gravestones of married couples who had been buried in the same grave. This study would not have been possible if these dates had been omitted. Disguising data presents even greater difficulties. There is a story, perhaps apocryphal, of an eminent psychiatrist who used the sex ratios reported in a family with multiple members affected by psychosis to sustain a particular hypothesis, only to be told at a meeting where he presented a paper that the authors had switched the sexes of the family members in order that the family could not be identified.

Raising difficult questions is not, in itself, particularly helpful. Trainees are likely to begin their publication career with a case report, and I would be reluctant for further obstacles to be put in their way. The right answer is not to publish case reports if they raise ethical dilemmas, but authors may need 
some help in resolving them. The guidelines are a valuable map, but leave some ethical problems untouched. A researcher has the opportunity to discuss ethical difficulties with an ethics committee. It would be helpful if contributors to the $B J P$ could similarly have recourse to ethical, as well as scientific, advice. Increasingly, reviewers of papers spend their time advising authors about the content of their papers and even about the statistical methods used. I suggest that the Editor asks the reviewers of case reports to consider the ethical implications as well as the clarity and scientific value of reports. This will not absolve the authors of their responsibility to the patient or family whose personal details they are reporting. It may, however, remove the obstacles to publication, and potential scientific advance, that the guidelines might occasionally introduce.

\section{Legal opinion}

\section{Bridgit Dimond}

At present, there is no legal right to privacy recognised in the UK. However, each health professional owes a duty to preserve the confidentiality of information concerning the patient. This duty is accepted by all health professions and is explicitly recognised by the General Medical Council and the British Medical Association. It is enforceable by the patient through an action for breach of trust and breach of the duty of care in negligence. It is also enforceable by the employers of the professional as a breach of the contract of employment. Professional conduct committees would also see unjustifiable disclosure as misconduct by the practitioner, which could in certain circumstances lead to professional conduct proceedings. To publish details relating to the patient who can be identified thereby is therefore prima facie actionable in a court of law or professional conduct proceedings, by the patient, by the employer, and by the registration body, unless authorised by a recognised exception.

There are many exceptions to this duty to maintain confidentiality. The relevant exceptions here include:

\section{(a) Consent by the patient}

If the patient agrees to the information being disclosed, then this would be a defence to an action for breach of confidentiality. It would be important to clarify the competence of the patient to give consent and also any limitations on what can be disclosed.

If the patient gives consent to the publication of a case study relating to his/her care, this would be a defence against any allegation of breach of confidence. However, it would be advisable to obtain the patient's consent in writing and to show that the patient was aware of the format of the case study and the form of publication.

\section{(b) Disclosure in the interests of the patient}

Information is passed between different professionals caring for the patient, in the interests of the patient. This is a recognised exception to the duty of confidentiality. It is unlikely that the publication of a case study about a patient could be regarded as being in the interests of the patient. There may be some indirect benefit, for example if, as a result of the sharing of information, advances in treatment and care are made which subsequently benefit the patient. This argument would apply to any research which is indirectly related to the patient's condition, but this fact would not justify ignoring the need to obtain the patient's consent in carrying out research. It is, therefore, unlikely that a defence of disclosure in the patient's interests would justify unauthorised disclosure.

\section{(c) Disclosure in the public interest}

Most registration bodies would recognise that there is a duty to disclose information which has been obtained in confidence if it is justified in the public interest. The case of W. $v$. Edgell (1990 1 All ER 835 ) is an example where the courts held that an independent psychiatrist was justified in disclosing his adverse report on the patient to the managers of the hospital and the Secretary of State, who referred it to a mental health review tribunal. The grounds for disclosure was the public interest.

It is in the public interest for professionals to carry out research and undertake education. However, this is probably too vague a justification for the publishing of intimate confidential details about the patient in scientific journals. There are other ways of educating professionals and undertaking research which does not breach the rules relating to confidentiality.

\section{Conclusion}

The only safe way as the law stands at present in the publishing of case studies is to obtain the patient's consent or write them up in such a way that no disclosure takes place.

Any attempt to justify disclosure on the basis of public interest would not be supported by the decision in W. $v$. Edgell. Other authority would have to be found.

\section{The Editor's decision is final ...}

\section{Greg Wilkinson}

As Editor, I sought independent advice on my position in law and I have been advised to ensure 
that I have adequate legal protection. I have been advised to ensure that $I$ am indemnified by the $B J P$ and its publishers because, as the Editor, I am the person responsible for the $B J P$.

Any contributor reading the current guidelines can be under no doubt of what he or she should do. The guidelines make it clear that consent should be obtained, and that if it is not, adequate attempts should be made to ensure that the patient's identity is disguised.

If an article is accurate and does not contain gratuitous comment, then a defence of justification or fair comment should be successful. As Editor, I would need to ensure that there is no gratuitous comment. An action for defamation will lie against the publisher and Editor, too, because they have repeated the defamation.

Accuracy would not protect against an allegation of breach of confidentiality. There would be such a breach if the patient could legitimately be identified by him/herself and/or by others. An action for breach of confidentiality will lie against the person responsible for that breach. This includes the author of the article or case report but probably not the publisher or Editor of the BJP.

I asked Professor Dimond four questions and her responses are given below.

(a) To what lengths do we need to go to disguise the identity of a patient, given that there is always a possibility, however small, that he/ she might be recognised?

All reasonable steps should be taken to ensure that there is no breach of confidentiality and that the patient could not recognise her/himself and nor could others.

(b) In what way and to what extent might we be held liable if a patient is identified? If the patient is able to recognise her/himself then the professional who gave that information to the BJP could face an action for breach of confidence. The Editors and publishers might also be liable as co-defendants with the professional. However, the patient would have to prove that they owed a duty of care to maintain confidentiality of the patient's information. In the case X v. Y (1988) (2 All ER
648) newspapers were prevented from disclosing the names of two doctors who had AIDS.

(c) Is there any difference in this instance between a case in which a patient identifies him/herself and one in which the patient is identified by others? The breach exists in the disclosure or passing on of the confidential information. This would apply whoever makes the identification.

(d) Is the present wording of our instructions to authors adequate; if not, what changes should we make, and is there any wording which would give us legal protection if such were required? Under paragraph headed "General", the first two sentences of the last paragraph are correct. Perhaps the last two sentences could be replaced by the words "Where the patient refuses to give consent then the case study can only be written up if personal details and dates and other information which identify the patient are omitted to ensure that there is no breach of confidentiality."

On the basis of the advice I have received I have decided to adopt Professor Dimond's advice on the fourth question (see Appendix) and to add a further sentence to our guidelines: "Contributors should be aware of the risk of complaint by patients in respect of defamation and breach of confidentiality and where concerned should seek advice".

\section{Appendix}

\section{New guidelines on case reports and confidentiality}

"If an individual patient is described, his or her consent should be obtained. The patient should read the report before submission. Where the patient is not able to give informed consent, it should be obtained from an authorised person. Where the patient refuses to give consent, then the case study can only be written up if personal details and dates and other information which identify the patient are omitted to ensure that there is no breach of confidentiality. Contributors should be aware of the risk of complaint by patients in respect of defamation and breach of confidentiality, and where concerned should seek advice."

Greg Wilkinson, FRCPsych, Editor, BJP; Tom Fahy, MRCPsych, Academic Department of Psychological Medicine, King's College Hospital, London; Gerald Russell, FRCPsych, Eating Disorders Unit, Hayes Grove Priory Hospital, Hayes, Kent; David Healy, MRCPsych, Academic Sub-department of Psychological Medicine, North Wales Hospital, Denbigh; Isaac Marks, FRCPsych, Institute of Psychiatry, London; Digby Tantam, FRCPsych, Section of Psychological Medicine, University of Warwick, Coventry; Bridgit Dimond, AHSM, University of Glamorgan, Cardiff 